\title{
Empleos verdes en la Argentina: oportunidades para avanzar en la agenda ambiental y social
}

\author{
Christoph Ernst, Ana Sofía Rojo Brizuela y Daniele Epifanio
}

\section{Resumen}

La economía argentina se vuelve más verde debido a una nueva orientación política, a los compromisos internacionales (Acuerdo de París y Agenda 2030 para el Desarrollo Sostenible) y a las iniciativas privadas. Esta transición tiene impactos económicos y sociales. Aquí se busca determinar el potencial de la economía para crear empleos verdes que protejan al ambiente y al trabajador. En 2015, el 7\% de los empleos formales eran verdes y presentaban en promedio mejores condiciones laborales. Predominaban en las actividades de producción de bienes y prestación de servicios urbanos, como saneamiento y transporte. Las regulaciones y políticas públicas parecen ser los principales factores que promueven la creación del empleo verde; el consumo aún juega un papel menor. Para que la transición hacia una economía verde sea justa, las políticas deben considerar la dimensión laboral para iniciar un círculo virtuoso hacia una economía más productiva, inclusiva y favorable al ambiente.

\section{Palabras clave}

Empleo, medio ambiente, cambio climático, economía ambiental, creación de empleos, trabajo digno, protección ambiental, desarrollo sostenible, estadísticas del empleo, Argentina

\section{Clasificación JEL}

J01, Q01, 001

\section{Autores}

Christoph Ernst es Epecialista en Empleo y Desarrollo Productivo en la Oficina de País de la Organización Internacional del Trabajo (OIT), Argentina. Correo electrónico: ernst@ilo.org.

Ana Sofía Rojo Brizuela es Licenciada en Economía de la Universidad de Buenos Aires, Argentina. Correo electrónico: sofia.rojo.sr@gmail.com.

Daniele Epifanio es Licenciado en Ciencias Políticas de la Universidad Libre Internacional de Estudios Sociales Guido Carli, Italia. Correo electrónico: danepi91@gmail.com. 


\section{Introducción}

El cambio climático es uno de los principales desafíos que enfrentará la humanidad en los próximos decenios. Sus consecuencias económicas, sociales y ambientales ponen en riesgo a vastos sectores de la población del planeta, en particular, en las regiones más pobres. En respuesta, los países definieron una agenda de política ambiental que puede tener efectos tanto positivos como negativos en la sociedad y su economía.

Por su posición geográfica y estructura productiva, la Argentina resulta particularmente afectada. Los desastres naturales, como las inundaciones (fluviales y ribereñas), las sequías, las temperaturas extremas y los incendios son cada vez más frecuentes. La actividad agropecuaria, fundamental en el desarrollo nacional y en el suministro de alimentos a nivel mundial, es la más vulnerable a estos fenómenos. La seguridad energética es otro aspecto sensible, ya que se ve afectada por la intensidad y duración cada vez mayores de las olas de calor. Las actividades urbanas en general sufren permanentemente los efectos negativos (MAyDS, 2017b).

Debido a la necesidad de adaptar los sistemas y sectores más vulnerables a la agenda internacional ambiental y a la creciente conciencia sobre la necesidad de respetar el entorno, en la Argentina se están implementando políticas en pro de una economía más verde. Diversos actores impulsan este cambio de paradigma: la voluntad política de los distintos niveles de gobierno; el sector productivo, muchas veces motivado por las exigencias de los mercados externos, y la sociedad en general, donde aún son incipientes las prácticas de consumo responsable (Voices Research and Consultancy, 2016).

La transición hacia una economía verde conlleva numerosas oportunidades y desafíos. La incorporación de los cambios tecnológicos, el estímulo a la innovación, la inversión en la infraestructura y el desarrollo de las cadenas de valor asociadas con el surgimiento de nuevos sectores son procesos que brindan la oportunidad de crear empleos con nuevos perfiles laborales, a la vez que se adaptan las competencias ocupacionales de los perfiles actuales (Altenburg y Assmann, 2017; OECD, 2017). Para aprovechar la oportunidad, es preciso formular políticas, crear incentivos y establecer marcos institucionales que mejoren la gestión de los recursos y contribuyan a la transición. En vista de los desafíos, algunos sectores deberán transformarse de forma inevitable. La transición hacia una economía verde será justa en la medida en que resulte inclusiva. La creación de trabajo decente en las nuevas actividades y la aplicación de políticas de protección social para atenuar los efectos en los sectores que deben transformarse son los principales canales que garantizan esa inclusión.

Se consideran empleos verdes a aquellos que, reuniendo los requisitos del trabajo decente, contribuyen a preservar y restaurar el medio ambiente. Pueden pertenecer a los sectores tradicionales, como la manufactura o la construcción, o a nuevos sectores emergentes, como las energías renovables y la eficiencia energética (Jarvis, Varma y Ram, 2011). Los empleos verdes son cruciales para una transición justa.

El estudio del empleo verde en la Argentina se enfoca en los puestos de trabajo que dicha transición permite crear e indica, entre sus resultados, que en 2015 el país contaba con unos 650.000 empleos de estas características, equivalentes al 7\% de los asalariados formales (OIT, 2017). El estudio forma parte de la iniciativa Programa Empleos Verdes de la Organización Internacional del Trabajo (OIT), que ha llevado a cabo investigaciones similares en distintos países, entre las que se destacan las experiencias de la Argentina, el Brasil, México y el Uruguay en América Latina (OIT, 2009, 2013a, 2016, 2017). El presente artículo se basa en el mencionado estudio del empleo verde en la Argentina, a la vez que profundiza en aspectos como ¿cuáles son los sectores donde se crean los empleos verdes?, ¿para qué perfiles de trabajadores?, ¿cuál es la calidad de ese empleo? y muestra la interdependencia entre la dimensión ambiental, productiva y laboral. Además, se busca demostrar 
que en países con estructuras productivas como la de la Argentina, los cambios hacia una mayor sostenibilidad ambiental son compatibles con un mayor desarrollo productivo y con la creación de trabajo decente, en particular, si se coordinan las políticas ambientales, productivas y laborales.

El artículo está estructurado de la siguiente manera. En primer lugar, se presentan las principales aristas del debate sobre la transición justa hacia una economía más sostenible, a la vez que se destaca el rol que deben cumplir los empleos verdes en la transición y se define el concepto de empleo verde. En segundo lugar, se presentan las estimaciones del empleo verde en el país por medio de un análisis sectorial. En tercer lugar, se discute la vinculación entre la política ambiental, productiva y laboral. Finalmente, se presentan las conclusiones.

\section{Desarrollo sostenible y creación de trabajo decente}

La preocupación por el cambio climático ha estado presente en los ámbitos internacionales desde hace casi medio siglo. La Agenda 2030 para el Desarrollo Sostenible, aprobada por la Asamblea General de las Naciones Unidas en septiembre de 2015, y los 17 Objetivos de Desarrollo Sostenible (ODS) asociados a esta Agenda otorgan un nuevo impulso a las estrategias globales para erradicar la pobreza, proteger el planeta y asegurar la prosperidad para todos.

En este nuevo paradigma, las instituciones y las políticas públicas se articulan en torno a un gran impulso ambiental que transforma la estructura productiva y de consumo y favorece la incorporación de los avances técnicos, la sostenibilidad y la igualdad. Este panorama brinda la oportunidad de crear empleos de calidad, aumentar la productividad - lo que permitiría volver más sostenibles las políticas sociales - y fortalecer los sistemas de ingreso mínimo universal, los seguros de desempleo y los mecanismos de protección y reinserción. De esta manera, se puede promover un proceso de transición justa de la fuerza de trabajo hacia economías y sociedades sostenibles (OIT, 2011, 2016; CEPAL, 2016).

\section{Efectos del cambio climático y de la política ambiental sobre el empleo: la necesidad de una transición justa}

Son numerosos los efectos del cambio climático en el mercado de trabajo. La elevada frecuencia de los fenómenos meteorológicos extremos afecta el empleo urbano; por ejemplo, los daños en el sistema de transporte, la infraestructura y los asentamientos disminuyen la capacidad de los trabajadores para conmutar o hallar alternativas de empleo. La agricultura, el turismo, los seguros, la silvicultura, la pesca, la infraestructura y la energía son algunos de los sectores más vulnerables a los efectos directos del cambio climático, ya que dependen del clima (OIT, 2010). El concepto de vulnerabilidad está muy asociado a la falta de estrategias de adaptación, frecuente entre la población más pobre.

Las políticas de adaptación pueden iniciar un círculo virtuoso que impulsa el empleo local: evitan la pérdida de puestos, al cambiar la forma de producción amenazada por el cambio climático, y crean empleos, al preparar al país para el cambio climático (particularmente, con obras de infraestructura). Los esfuerzos de mitigación, encaminados a reducir las emisiones de gases de efecto invernadero (GEI), modifican ciertos sectores de la economía, principalmente aquellos vinculados con la producción de energía mediante combustibles fósiles y los que requieren abundante energía. Estos últimos son, por ejemplo, las industrias del acero, el hierro y el aluminio y el servicio del transporte por carretera. 
Los cambios en las normas comerciales también inciden sobre el empleo, ya que la creciente sensibilización de los consumidores puede producir cambios en los modelos de consumo y, por ende, en los mercados de trabajo. Otro efecto es el desplazamiento de los empleos como consecuencia de la fuga de carbono, como se denomina al desplazamiento de las inversiones hacia los territorios en los que las normas medioambientales son menos estrictas. El cambio climático también puede producir corrientes migratorias desde las áreas rurales, donde las capacidades productivas se han visto afectadas, hacia las ciudades.

La política ambiental tiene claros efectos sobre el tejido productivo, fusionándose en algunos casos con la política industrial verde. En efecto, algunas medidas inducen innovaciones en los procesos y, particularmente las vinculadas con la política energética, promueven transformaciones en la estructura productiva para volverla baja en carbono, eficiente en el uso de los recursos y más productiva (Altenburg y Rodrik, 2017).

Por lo anteriormente expuesto, es posible afirmar que la transición hacia una economía más verde afectará al empleo de cuatro maneras: i) se crearán empleos en nuevos sectores verdes emergentes, como las energías renovables, donde la demanda de bienes y servicios se está expandiendo; ii) se eliminarán ciertos empleos sin sustitución directa, por ejemplo, al prohibir o desalentar el uso de determinados métodos; iii) algunos empleos serán sustituidos como consecuencia de la transformación industrial; y iv) la mayoría de los puestos de trabajo de la actualidad se transformará y redefinirá en función de los nuevos requisitos de perfil y métodos de trabajo (PNUMA y otros, 2008).

Las consideraciones anteriores ilustran con claridad que estos procesos brindan oportunidades, pero también acarrean fuertes riesgos para algunos sectores del empleo. En este sentido, el concepto de transición justa, que tuvo sus orígenes en el movimiento sindical y que ha sido adoptada en la actualidad por los organismos especializados del sistema de las Naciones Unidas y los gobiernos, plantea que el cambio hacia una economía más verde debe tener en cuenta a todos los agentes involucrados. El diálogo social debe situarse en el centro del proceso, y los gobiernos, además de regular las emisiones de GEl, deben jugar el papel fundamental de promover el tipo de políticas industriales y sociales que conduzcan a la creación del empleo productivo y decente (OIT, 2015).

\section{Empleo verde}

En los últimos años, varios responsables de la formulación de políticas, grupos de sensibilización e investigadores han celebrado debates sobre el potencial de las políticas climáticas para la creación de empleos verdes. Estos se definen como los empleos que, alcanzando los estándares de trabajo decente, contribuyen a preservar y restaurar el medio ambiente en los sectores tradicionales, como la manufactura o la construcción, o en nuevos sectores emergentes, como las energías renovables y la eficiencia energética (Jarvis, Varma y Ram, 2011). El diagrama 1 ilustra ese concepto.

El trabajo decente es un concepto formulado por la OIT que establece las características que debe reunir una relación laboral para que el trabajo se realice "en condiciones de libertad, igualdad, seguridad y dignidad humana". Para que el trabajo sea decente, es necesario que el trabajador tenga: 1) un trabajo productivo con un salario justo, 2) buenas condiciones laborales, 3) protección social, 4) derechos laborales, 5) igualdad de oportunidades entre géneros y 6) acceso y participación en las decisiones que afectan su vida. (OIT, 2012). 
Diagrama 1

Definición de empleo verde

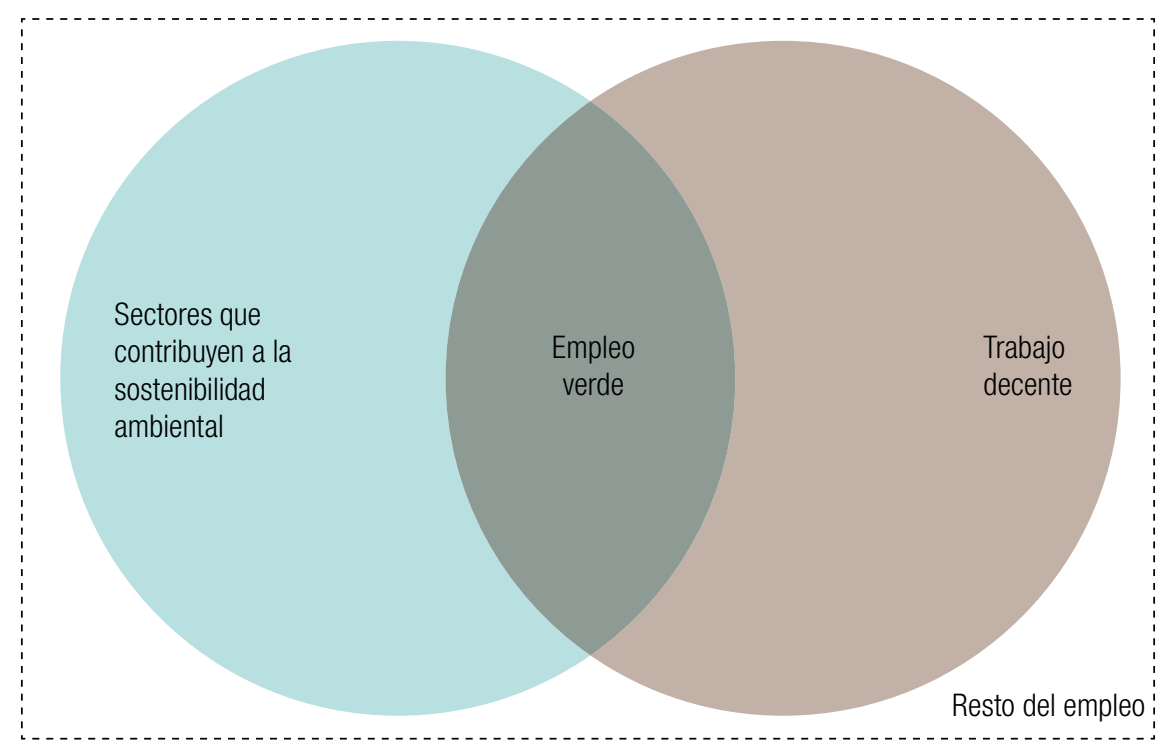

Fuente: A. Jarvis, A. Varma y J. Ram, Assessing Green Jobs Potential in Developing Countries: A Practitioner's Guide, Ginebra, Organización Internacional del Trabajo (OIT), 2011.

A nivel empresarial, los empleos verdes pueden producir bienes o prestar servicios que beneficien al medio ambiente, como el saneamiento del agua o la reforestación. También, sin producir necesariamente bienes o servicios ambientales, pueden contar con procesos de producción más respetuosos con el medio ambiente, por ejemplo, reduciendo el consumo de agua o mejorando el sistema de reciclaje. Estos empleos son los que reducen el impacto ambiental de las empresas y de los sectores económicos hasta alcanzar, en definitiva, niveles sostenibles (PNUMA y otros, 2008).

A partir de la presencia de ambos atributos, trabajo decente y sostenibilidad ambiental, es posible clasificar el universo del empleo en cuatro grandes situaciones.

El empleo verde, como ya se ha mencionado, reúne las condiciones de trabajo decente y sostenibilidad ambiental.

El empleo ambiental (no verde) se desempeña en los sectores que siguen prácticas ambientales sostenibles, pero no alcanzan los estándares laborales adecuados para ser considerado empleo verde. Ejemplos de empleos ambientales no verdes son: el trabajo informal, estacional y sin las preceptivas medidas de seguridad que se desempeña en algunos sectores de la agricultura orgánica; el trabajo de los recolectores y recicladores urbanos, cuando se desempeña en condiciones inadecuadas, y la labor de los trabajadores informales que construyen pequeñas obras para una mejor gestión del agua. Este tipo de empleo tiene un inmenso potencial de volverse un empleo verde si se mejoran su productividad y condiciones laborales.

Las dos situaciones restantes corresponden, por un lado, a los sectores donde el trabajo es decente pero no se satisfacen las condiciones de sostenibilidad ambiental (ausencia de políticas ambientales) y, por otro, a los sectores donde ambas condiciones, laborales y ambientales, resultan inadecuadas. 
Diagrama 2

Relación entre el trabajo decente y la sostenibilidad ambiental

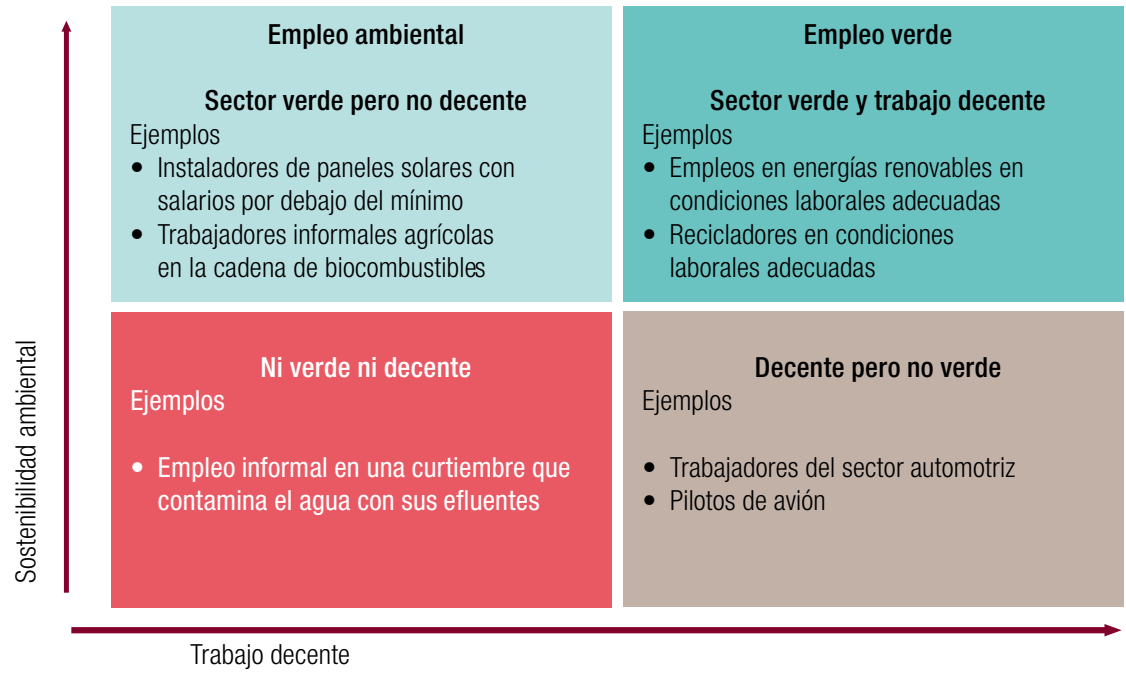

Fuente: A. Jarvis, A. Varma y J. Ram, Assessing Green Jobs Potential in Developing Countries: A Practitioner's Guide, Ginebra, Organización Internacional del Trabajo (OIT), 2011.

Si bien la definición de empleo verde de la Organización Internacional del Trabajo (OIT) y el Programa de las Naciones Unidas para el Medio Ambiente (PNUMA) está ampliamente difundida, hay numerosos aspectos en debate respecto de cómo hacerla operativa. ¿El empleo verde se debe estimar a nivel ocupacional, empresarial o sectorial?, ¿se debe restringir a las industrias que producen bienes y servicios ambientales o se debe ampliar a los otros sectores del tejido productivo que ejercen buenas prácticas ambientales?, ¿se debe considerar el empleo directo o todo el empleo generado en las cadenas de valor de los sectores verdes? son las principales preguntas que alimentan las discusiones.

Algunos estudios se enfocan en las ocupaciones que tienen un objetivo claramente ambiental (Keivani y otros, 2010). No obstante, resulta complejo identificarlas cuando son ocupaciones tradicionales que se desempeñan en las actividades ambientales (un obrero metalúrgico que produce turbinas para la energía eólica). Otros estudios se centran en las actividades productivas, restringiendo el empleo verde a la industria de bienes y servicios ambientales o, desde una lógica de reverdecimiento del tejido productivo, incluidos los subsectores y empresas que ejercen buenas prácticas ambientales en los sectores tradicionales (OECD/Eurostat, 1999; PNUMA y otros, 2008).

El enfoque de las ocupaciones ofrece grandes ventajas, ya que permite cuantificar el empleo verde que se crea en los sectores marrones, que suelen realizar grandes esfuerzos para mejorar su desempeño ambiental (obligados por las regulaciones o por los mercados). En este sentido, parece el criterio más adecuado. No obstante, requiere esfuerzos metodológicos y fuentes de información sobre las ocupaciones que habitualmente no se encuentran disponibles.

Siguiendo la metodología propuesta por el Programa Empleos Verdes de la OIT (Jarvis, Varma y Ram, 2011), que resulta la más adecuada para las fuentes de información disponibles, se estimó el empleo verde en la Argentina por sector y empresa. Se profundiza este aspecto en el anexo.

Por esta razón, la estimación para la Argentina subestima el empleo verde total, ya que no incorpora las ocupaciones verdes que se desempeñan en los sectores marrones, debido a la imposibilidad de cuantificarlas a partir de las fuentes de información disponibles. 


\section{Empleo verde en la Argentina: patrones sectoriales e implicancias sobre la calidad del empleo}

Con un producto interno bruto (PIB) de 546.000 millones de dólares (2016), la Argentina es una de las economías más grandes de América Latina. Tiene abundantes recursos naturales en materia de energía y agricultura, es líder en la producción de alimentos y tiene oportunidades en algunos subsectores de manufacturas y en los servicios innovadores de alta tecnología.

En 2016, el 9\% del PIB correspondió a la agricultura, la ganadería, la silvicultura y la pesca, y el $21 \%$ a la industria manufacturera (del cual, a su vez, el $25 \%$ a los alimentos y las bebidas). La población ascendía a 44 millones de habitantes con una tasa de desempleo del $8,5 \%{ }^{1}$ y $10 \%$ de subocupación. El empleo informal (porcentaje de asalariados no registrados) alcanzaba el 33,8\% (MTEySS, s/f).

Durante los últimos 15 años, la Argentina transitó un proceso de crecimiento económico impulsado por los sectores primarios e industrial que permitió incorporar más personas al consumo, principalmente, a partir de empleos formales. El marco institucional -caracterizado por las políticas orientadas a promover la formalización del empleo, el diálogo social y la consolidación del salario mínimo, vital y móvil y de la negociación colectiva - contribuyó a que esta etapa de crecimiento económico estuviera acompañada de un proceso de inclusión social (Bertranou y Casanova, 2013). En efecto, entre 2000 y 2016, el empleo asalariado registrado se incrementó en un 63\%, superando el crecimiento del PIB en moneda constante (47\%) como resultado, en parte, de la creación de nuevos puestos de trabajo y de la formalización de los empleos no registrados.

Gráfico 1

Evolución del producto bruto interno (PIB), el empleo asalariado registrado privado y la tasa de empleo no registrado, 2000-2016

(Índice 2000=100)

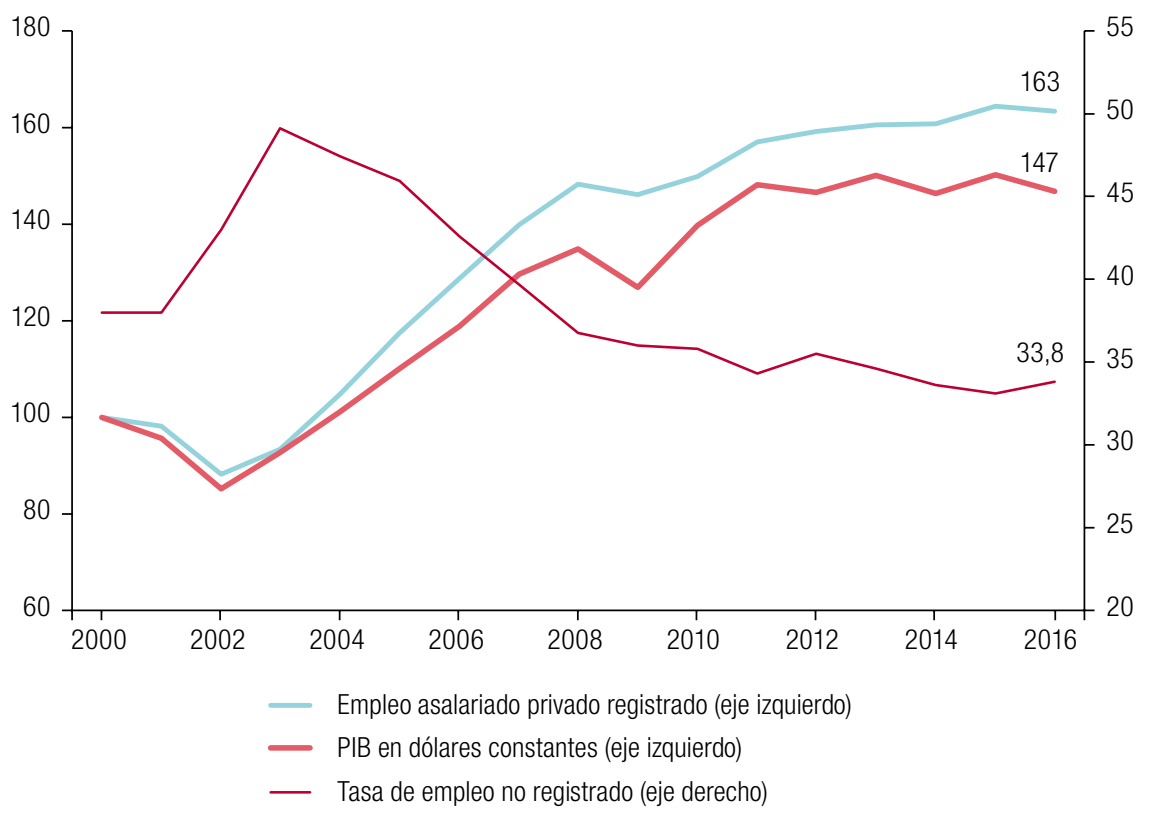

Fuente: Elaboración propia, sobre la base de la Encuesta Permanente de Hogares (INDEC) y el Ministerio de Trabajo, Empleo y Seguridad Social (MTEySS).

\footnotetext{
1 Tercer trimestre de 2016.
} 
La intensidad y el tipo de crecimiento, impulsado por la expansión de las actividades agropecuarias y manufactureras, tuvo también consecuencias ambientales adversas. Tal vez el principal problema fue la desforestación que se llevó a cabo en el norte del país debido al avance de la frontera agrícola. En 2014, el 39,6\% de las emisiones de gases de efecto invernadero correspondió a la producción de energía, seguida por la agricultura y la ganadería $(26,9 \%$ y el cambio de uso de suelo y la silvicultura $(25,7 \%)$. Aunque en menor medida, la gestión de los residuos $(4,4 \%)$ y los procesos industriales (3,3\%) también generaron GEI (SAyDS, 2015).

La pérdida de enormes extensiones de bosques no solo incrementó las emisiones de GEI, sino que también contribuyó al aumento de la frecuencia y la intensidad de las inundaciones que, año tras año, afectan a la población (FAO, 2014; Banco Mundial, 2016). Asimismo, la contaminación del aire, la gestión de los residuos y la contaminación del agua han pasado a ser graves problemas, en particular, en los centros urbanos (Banco Mundial, 2016).

Desde 2000 se vienen intensificando los esfuerzos para promover una transición hacia trayectorias de crecimiento con mayor sustentabilidad ambiental, tanto por parte de las políticas públicas como por parte de las iniciativas privadas, muchas veces promovidas por los requerimientos de los mercados de exportación. Entre estos esfuerzos, se puede mencionar la Ley 25.675, denominada Ley General del Ambiente (2002), que establece los presupuestos mínimos para lograr una gestión sostenible y adecuada del medio ambiente y que enmarca diferentes regímenes sectoriales. El resultado de estos esfuerzos se refleja en un menor aumento en las emisiones de GEI $(0,4 \%)$ respecto del PIB $(2,8 \%)$, considerando tasas promedio anuales para el período 2000-2014. Este proceso resulta más evidente a partir de 2009, cuando las emisiones se redujeron - en un contexto de estancamiento del PIBdebido, principalmente, a un menor ritmo de desforestación, a la caída de la producción ganadera y a la reducción de las emisiones en el sector de energía.

A partir del cambio de gobierno en 2016, los esfuerzos hacia una mayor sostenibilidad ambiental se intensificaron. Se adoptó una política energética más activa, se redujeron los subsidios a los precios de la energía y de los combustibles y se incentivó la inversión en las fuentes de energía renovable (Programa RenovAr). La puesta en marcha de las obras de infraestructura orientadas a prevenir las inundaciones y el desarrollo de los sistemas de monitoreo de catástrofes (Plan Nacional del Agua) reducen la vulnerabilidad de vastos sectores, a la vez que crean empleos verdes. Asimismo, se busca mejorar la eficiencia ambiental del sistema de transporte urbano de pasajeros mediante la ampliación de las redes de metro y la infraestructura urbana.

La transición hacia patrones de crecimiento con mayor sostenibilidad social y ambiental crea nuevas actividades y ocupaciones que se suman a las tradicionales. Muchos de estos empleos se consideran empleos verdes, es decir, trabajo decente que se desempeña en actividades ambientalmente sostenibles.

\section{Configuración sectorial del empleo verde}

Los empleos verdes se hallan en prácticamente todos los sectores de la economía argentina. Algunos sectores se consideran verdes por definición, como los de saneamiento y protección ambiental, mientras que, en el resto del tejido productivo, los empleos verdes se encuentran en actividades donde se ejercen prácticas ambientales sostenibles como, por ejemplo, la agricultura orgánica, los procesos industriales energéticamente eficientes y las actividades de investigación enfocadas en los aspectos ambientales ${ }^{2}$.

\footnotetext{
2 Los aspectos metodológicos de la estimación del empleo verde en la Argentina se detallan en el anexo de este artículo.
} 
En 2015, se estima que existían entre 486.000 y 650.000 empleos verdes en la Argentina, que representaban el $4 \%$ y el $7 \%$ de los asalariados registrados, respectivamente. La diferencia entre ambas estimaciones depende de si se considera o no "verde" el empleo que se desempeña en el transporte automotor público de pasajeros.

Es oportuno remarcar que esta estimación no incluye los empleos ambientales del sector informal de la economía, los que no se consideran "empleos verdes" porque presentan condiciones laborales inadecuadas. Este tipo de empleo plantea los desafíos de mejorar su productividad y de garantizar el acceso a los derechos laborales.

Los asalariados registrados en los sectores y empresas "no verdes" figuran en el cuadro 1. Con las fuentes disponibles, no fue posible cuantificar el empleo verde que se desempeña en el interior de dichas empresas "no verdes", por lo que hay un sesgo de subestimación.

Considerando la estimación amplia (650.000), la mayor parte del empleo verde se concentra en la industria manufacturera (38\%), el transporte (29\%), la rama de la agricultura, la ganadería, la silvicultura y la pesca (9\%) y en el suministro de agua y gestión de los residuos (7\%). Las actividades de servicios y comercio vinculadas con la protección ambiental integran un 10\%. Bajo una hipótesis más restrictiva (486.000), la importancia relativa de los sectores cambia: cobran aún mayor importancia la industria manufacturera (50\%) y la rama de la agricultura, la ganadería, la silvicultura y la pesca (12\%) (OIT, 2017).

\section{Cuadro 1}

Argentina: composición sectorial del empleo verde, dos hipótesis de estimación, 2015

\begin{tabular}{|c|c|c|c|c|c|c|c|c|}
\hline & \multicolumn{2}{|c|}{$\begin{array}{l}\text { Asalariados } \\
\text { registrados } 2015\end{array}$} & \multicolumn{3}{|c|}{$\begin{array}{c}\text { Empleo verde } \\
\text { (estimación ampliaa) }\end{array}$} & \multicolumn{3}{|c|}{$\begin{array}{c}\text { Empleo verde } \\
\left.\text { (estimación restringida }^{b}\right)\end{array}$} \\
\hline & miles & $\begin{array}{l}\text { porcentaje } \\
\text { del total }\end{array}$ & miles & $\begin{array}{l}\text { porcentaje } \\
\text { del total }\end{array}$ & $\begin{array}{l}\text { porcentaje } \\
\text { del sector }\end{array}$ & miles & $\begin{array}{l}\text { porcentaje } \\
\text { del total }\end{array}$ & $\begin{array}{l}\text { porcentaje } \\
\text { del sector }\end{array}$ \\
\hline Agricultura, ganadería, silvicultura y pesca & 366 & 4 & 58 & 9 & 16 & 58 & 12 & 16 \\
\hline $\begin{array}{l}\text { Agricultura, ganadería, caza y } \\
\text { actividades de servicios conexas }\end{array}$ & 341 & 3 & 53 & 8 & 16 & 53 & 11 & 16 \\
\hline Silvicultura y extracción de madera & 11 & 0 & 3 & 1 & 30 & 3 & 1 & 30 \\
\hline Pesca y acuicultura & 15 & 0 & 2 & 0 & 11 & 2 & 0 & 11 \\
\hline Explotación de minas y canteras & 97 & 1 & - & 0 & 0 & - & 0 & 0 \\
\hline Industrias manufactureras & 1274 & 13 & 245 & 38 & 19 & 245 & 50 & 19 \\
\hline $\begin{array}{l}\text { Suministro de electricidad, gas, } \\
\text { vapor y aire acondicionado }\end{array}$ & 71 & 1 & 11 & 2 & 15 & 11 & 2 & 15 \\
\hline $\begin{array}{l}\text { Suministro de agua, evacuación de } \\
\text { aguas residuales, gestión de desechos }\end{array}$ & 59 & 1 & 48 & 7 & 83 & 48 & 10 & 83 \\
\hline Construcción & 475 & 5 & 23 & 3 & 5 & 23 & 5 & 5 \\
\hline Transporte y almacenamiento & 476 & 5 & 188 & 29 & 39 & 24 & 5 & 5 \\
\hline $\begin{array}{l}\text { Actividades de alojamiento y } \\
\text { de servicio de comidas }\end{array}$ & 278 & 3 & 16 & 2 & 6 & 16 & 3 & 6 \\
\hline $\begin{array}{l}\text { Comercio y otros servicios no analizados } \\
\text { (personales y empresariales) }\end{array}$ & 6844 & 69 & 62 & 10 & 1 & 62 & 13 & 1 \\
\hline Total & 9939 & 100 & 650 & 100 & 7 & 486 & 100 & 5 \\
\hline
\end{tabular}

Fuente: Elaboración propia, sobre la base de la Organización Internacional del Trabajo (OIT), Estimación del empleo verde en Argentina, Buenos Aires, 2018.

a Incluye el empleo del transporte automotor de pasajeros.

b Excluye el empleo del transporte automotor de pasajeros. 
Para agilizar el análisis, se agruparon, a continuación, las actividades económicas en cuatro grandes grupos o subsistemas según las problemáticas centrales que estas comparten: i) la explotación de los recursos renovables, ii) la producción de energía y combustibles, iii) la industria manufacturera y iv) los sistemas urbanos. El análisis sectorial que se presenta a continuación está basado en la Estimación del empleo verde en la Argentina (OIT, 2017).

\section{a) Explotación de los recursos renovables}

El primer subsistema que se analizará es la explotación de los recursos renovables, conformado por la agricultura, la ganadería, la pesca y la silvicultura. En 2015, estas actividades representaron el 9\% del PIB, el 7\% del empleo formal y el 23\% de las exportaciones de la Argentina. Si se consideran los encadenamientos de las agroindustrias, la incidencia del sector primario en la economía nacional es aún mayor (Rodríguez, 2005). También contribuyen, en gran medida, a la subsistencia de las poblaciones rurales que cuentan con recursos escasos - este es el caso, en particular, de la pesca, el sector forestal y la agricultura a pequeña escala. Las condiciones laborales para los trabajadores de estos sectores tienden a ser más precarias que para el promedio de la economía: el trabajo es informal y no permanente (transitorio y estacional), y los riesgos del trabajo son mayores que en otras actividades (Ohaco, 2012; CIFRA, 2011).

Entre las buenas prácticas ambientales del sector agropecuario, además de la agricultura y la ganadería orgánica, se destacan las prácticas de conservación basadas en la incorporación de tecnología: principalmente, la agricultura de precisión, el control de la erosión a través de los sistemas de siembra directa y el control de la contaminación del suelo, del agua y del impacto sobre la biodiversidad. También cabe mencionar la gestión de los residuos, que se aprovechan cada vez más para la producción de energía (Viglizzo y Frank, 2010; Banco Mundial, 2016).

Por su parte, la protección de los bosques y los recursos pesqueros requiere el desarrollo de los regímenes de gobernanza pertinentes y de las instituciones que los apliquen. La Argentina cuenta con un modelo de gestión de los recursos sumamente sofisticado para ambos recursos, que crea una importante cantidad de empleos verdes públicos y privados en materia de monitoreo y control. Además, los productores orientados al mercado externo utilizan sellos específicos que certifican las buenas prácticas ambientales.

Para identificar a los productores que ejercen las buenas prácticas ambientales en estos sectores, se emplean tres estrategias. En el sector exportador, las buenas prácticas agrícolas, forestales y pesqueras se identifican por medio de sellos específicos que las certifican - principalmente, GlobalG.A.P (Good Agricultural Practices), RTRS (Roundtable on Responsible Soy), FSC (Forest Stewardship Council) y MSC (Marine Stewardship Council).

En general, en el mercado interno de la Argentina aún no se exige este tipo de certificaciones, que suele tener un costo elevado para el productor. Los productores orientados al mercado doméstico que ejercen las buenas prácticas agrícolas se afilian a las asociaciones de productores que son reconocidas por su firme compromiso ambiental, como el Programa Cambio Rural, la Asociación Argentina de Productores en Siembra Directa (Aapresid) y la Asociación Argentina de Consorcios Regionales de Experimentación Agrícola (AACREA).

La tercera estrategia está ligada a las actividades altamente reguladas, que requieren técnicos y profesionales con empleos verdes.

El subsector agroganadero aporta unos 58.000 empleos verdes, que representan el 16\% de sus asalariados formales. En los cultivos transitorios (los cereales, las oleaginosas, las hortalizas y los cultivos industriales, como la caña de azúcar y el algodón), el 15\% de los empleos es verde, mientras que en los cultivos permanentes (principalmente, las frutas), la incidencia del empleo verde es más elevada (38\%). En la ganadería, el 7\% del empleo formal es verde. 
El sector forestal cuenta con 3.300 trabajadores con empleos verdes (el 34\% del empleo formal del sector), que se desempeñan en las actividades de producción o como técnicos o profesionales. Se estima que, en el sector de la pesca, el número de empleos verdes asciende a unos 1.500 puestos, que representan el $21 \%$ del empleo formal. Los empleos verdes públicos en la pesca, encargados de gestionar el marco regulatorio del sector, son otros 2.400 puestos aproximadamente.

\section{b) Producción de energía y combustibles}

La matriz energética de la Argentina se encuentra actualmente dominada por los combustibles fósiles: el 53\% de la energía proviene del gas natural y el 33\% del petróleo. La participación del carbón mineral, por su parte, es muy baja, y las energías renovables representan el 10\% de la oferta primaria (MEN, 2016). Si bien la producción de energía renovable es aún una actividad incipiente en la Argentina, la elevada participación del gas lleva a que el sector energético resulte relativamente "limpio" en comparación con otras economías de la región. No obstante, el sector energético de la Argentina presenta problemas de seguridad en la disponibilidad del recurso (vinculados a la dependencia del gas y el petróleo), socioeconómicos (algunos sectores de la población no tienen acceso a la energía de red dada la superficie tan extensa del país) y ambientales (el gas natural es el principal generador de gases de efecto invernadero) (SAyDS, 2015).

En los últimos años, el desarrollo de las fuentes de energía renovable ha sido un área prioritaria para la política. En el país, se está buscando diversificar la oferta energética y mejorar la eficiencia en el uso de la energía a través de diversas medidas, como las reducciones en el subsidio al consumo, los incentivos a las inversiones en las fuentes renovables (como la ley de corte que promueve el uso de biocombustibles, el programa RenovAr y el programa PROBIOMASA) y los programas que facilitan el acceso al servicio energético en las poblaciones rurales.

En 2015, se estimaron unos 10.000 empleos verdes en pequeñas centrales hidráulicas (22\%), eólicas y solares, y en los sectores vinculados con la producción de bioenergías, como biodiesel y bioetanol (46\%) y otras formas de biomasa (24\%).

\section{c) Industria manufacturera}

La industria manufacturera argentina es un sector diversificado y tiene una participación importante en el PIB $(21 \%)^{3}$. Incluye a las agroindustrias que abastecen la totalidad de la demanda interna y que son un componente importante en las exportaciones. Además, comprende una variedad de actividades que van desde la producción de textiles, productos de metalmecánica, papel, el sector farmacéutico, productos químicos y petroquímicos, aluminio, acero y automóviles, hasta el desarrollo de aplicaciones biotecnológicas, instrumentos médicos y productos nucleares y espaciales.

Una característica del sector manufacturero de la Argentina es su elevada heterogeneidad productiva - cuenta con brechas de intensidad tecnológica, brechas de productividad, agentes de distinto tamaños, entre otros - que genera puestos de trabajo con condiciones laborales desiguales, en aspectos tales como el nivel de remuneraciones, el grado de informalidad y las oportunidades de inserción laboral para las mujeres en el empleo (Infante y Gerstenfeld, 2013). En 2015, la industria manufacturera empleaba unas 2.4 millones de personas, de las cuales el $79 \%$ eran asalariadas, de las cuales, a su vez, el 69\% estaban registradas.

Esa heterogeneidad también se refleja en el desempeño ambiental: los segmentos con baja productividad que no pueden financiar las condiciones laborales adecuadas para sus trabajadores tampoco pueden financiar las prácticas ambientales adecuadas.

3 Valor añadido en 2015, a precios de 2004. 
Para comprender el desempeño ambiental interesan ambas dimensiones: la brecha de productividad y el tipo de sector. La industria manufacturera comprende subsectores cuyos procesos productivos afectan negativamente el medio ambiente, sobre todo, a través de la emisión de GEl y la contaminación del agua, y, al mismo tiempo, grupos de empresas que realizan esfuerzos para avanzar hacia modos de producción más sostenibles (SAyDS, 2015).

Entre las buenas prácticas ambientales en la industria, predominan las acciones orientadas al uso de tecnologías más limpias y a la optimización de los costos. Algunas de las prácticas más utilizadas son el uso de combustibles alternativos y de materiales reciclados (papel y cartón, aluminio, hierro y acero, vidrio y plásticos) y el análisis del ciclo de vida de los productos (SAyDS, 2015; Stumpo y Rivas, 2013). La demanda de los mercados de exportación juega un rol significativo, motivando los procesos de incorporación de las tecnologías limpias y de los nuevos criterios de gestión ambiental por parte de los productores locales. Estas exigencias toman la forma de certificaciones de calidad con contenido ambiental, como las certificaciones de los productos orgánicos, las ISO 14000 y los sellos ecológicos.

Por otra parte, el desempeño ambiental de la industria no parece haber sido un tema central en la agenda política de las últimas décadas. En efecto, entre las buenas prácticas ambientales del sector, las de tratamiento de los efluentes, las emisiones y los residuos parecen tener un menor grado de aplicación.

La Argentina también produce numerosos bienes para uso ambiental, definidos según los criterios de la Organización para la Cooperación y el Desarrollo Económicos (OCDE) (Sugathan, 2013). Muchos de estos bienes forman parte de las cadenas de valor de las energías renovables y son objeto de políticas en una estrategia de desarrollo productivo con elementos de "política industrial verde" (INTI, 2013; SAyDS, 2015).

Los empleos verdes en la industria manufacturera se estiman en unos 245.000 (19\% de los asalariados formales del sector). Esta cifra se compone tanto de los empleos vinculados a la producción de bienes para usos ambientales como de los empleos en las empresas que siguen buenas prácticas ambientales. Un porcentaje significativo se vincula a la producción de alimentos y bebidas en cadenas de valor agroindustriales que tienen certificaciones ambientales durante la etapa primaria (OIT, 2017).

\section{d) Sistemas urbanos}

El cuarto subsistema comprende las actividades urbanas: la gestión de los residuos, el saneamiento de las aguas, el transporte y la construcción. El turismo también se incluye en este grupo porque, si bien el ecoturismo es rural, la mayor proporción de las actividades turísticas en la Argentina - hotelería, restaurantes y otros servicios - se desarrollan en los ámbitos urbanos.

El crecimiento económico y el acceso al consumo por parte de grupos sociales cada vez más grandes generan una mayor demanda de los sistemas urbanos. En la Argentina, el 92\% de la población es urbana (INDEC, 2010). En consecuencia, la cobertura y la calidad de estos sistemas tienen inciden significativamente en la calidad de vida de los ciudadanos y en la competitividad de la economía.

Debido a las grandes distancias y la baja densidad de población del país, el transporte es un servicio central tanto para la competitividad como para la calidad de vida de las personas. Desde la perspectiva ambiental, el sector resulta muy heterogéneo. El transporte automotor (de carga y pasajeros) es una de las actividades que genera más contaminación (GEl, ruidos, congestión, accidentes), al punto de condicionar la sustentabilidad de las ciudades, mientras que el ferrocarril o el transporte acuático constituyen alternativas más sostenibles. 
Se realizaron dos estimaciones del empleo verde para este sector, las que reflejan el debate sobre el desempeño ambiental del autotransporte público de pasajeros - si bien es una fuente importante de emisiones, supone una reducción significativa en las emisiones de GEl si se lo compara con el autotransporte privado. El primer modo explica el 13\% de las emisiones del sector del transporte, mientras que el segundo el 79\% (SAyDS, 2015). Así, desde la perspectiva amplia, los empleos verdes en el sector del transporte ascienden a unos 187.000 puestos de trabajo, lo que equivale al $29 \%$ de los asalariados registrados de la economía. Los subsectores propuestos son el ferroviario, el marítimo y fluvial, el transporte carretero público de pasajeros y el metro. Desde una perspectiva restringida, se estima que los empleos verdes en el sector representan solamente el $5 \%$ de los asalariados registrados.

En la Argentina, los sistemas de saneamiento y de gestión de los residuos deben incrementar su cobertura y la calidad de las prestaciones: la cobertura del agua potable alcanza al $83 \%$ de la población; el 91\% de los hogares - urbanos y rurales - cuenta con un servicio de recolección regular de los residuos - solo el 64,7\% de los residuos tiene una disposición adecuada-, y la cobertura cloacal alcanza al 49\% de la población (INDEC, 2010). La inadecuada disposición final de los residuos tiene efectos negativos sobre el aire y el agua. El sector emite el 4,4\% de los GEI (SAyDS, 2015).

Por su parte, la construcción emite grandes cantidades de GEl, debido a que su huella ecológica se extiende por toda la cadena de valor. No se ha diseñado aún en el país una estrategia que promueva de manera masiva la construcción de viviendas sostenibles. Por otra parte, parecen insuficientes las obras de infraestructura destinadas a mitigar los efectos del cambio climático.

La calidad del empleo en las actividades que componen los sistemas urbanos, en general, es menor que en la media de la economía. La construcción, la gestión de los residuos, algunos subsectores de transporte y el turismo presentan elevadas tasas de informalidad, condiciones precarias de trabajo y bajos requerimientos de calificación. En estas actividades, es común encontrar situaciones contrastantes: por un lado, un subsector formal con remuneraciones y cobertura de salud superiores al promedio de la economía y, por otro, un subsector informal que se desempeña en situaciones de extrema pobreza.

Las actividades de gestión de los residuos y saneamiento crearon unos 48.000 empleos verdes que representaban el $83 \%$ del empleo formal del sector. Por otra parte, en la construcción se crearon unos 22.000 empleos verdes (que equivalían aproximadamente al $4 \%$ de los asalariados registrados en el sector) en cinco actividades: la construcción de los edificios verdes, las obras de infraestructura hídrica, las obras de infraestructura para la generación de las energías renovables, la instalación de equipos para el uso de la energía solar térmica y las actividades de servicios profesionales.

Las actividades de turismo tienen los mismos problemas ambientales que el resto de las actividades del sistema urbano: la gestión de los residuos y del agua y la congestión parecen ser las principales externalidades ambientales negativas asociadas a esta actividad. Las principales actividades verdes del sector son: las buenas prácticas ambientales que ejercen algunos hoteles y agencias de turismo; las actividades que se llevan a cabo en las áreas protegidas, el ecoturismo y el turismo aventura; los servicios de los jardines botánicos; la gestión de los parques nacionales; el mantenimiento de los espacios verdes; y los servicios de las bibliotecas y los museos. Además, deben tenerse en cuenta las actividades culturales y recreativas, como las teatrales, de espectáculo y las que tienen lugar en los parques de diversiones, que se gestionan en condiciones de sostenibilidad. El turismo genera unos 16.000 empleos verdes (que representan solo el 6\% de los asalariados formales del sector).

Si bien no está asociado exclusivamente a ningún sector económico en particular, existe un conjunto numeroso de servicios empresariales que crean empleos verdes (62.000). Este conjunto está formado, en parte, por los organismos de regulación y fiscalización (28.000 empleos), las 
actividades vinculadas a los ensayos técnicos y las instituciones que investigan asuntos ambientales (9.000 empleos), el comercio de materiales reciclados (5.000 empleos) y las organizaciones sindicales y empresariales (4.000 empleos) (OIT, 2017).

\section{Calidad del empleo verde}

Como se ha mencionado y debido a la metodología utilizada para su estimación, el empleo verde en la Argentina es el porcentaje del empleo asalariado formal, es decir, del trabajo decente, que se desempeña en sectores que contribuyen a la sostenibilidad ambiental. Esto significa que alcanza determinados estándares de calidad.

No obstante, debido a su especialización sectorial —el empleo verde está sobrerrepresentado en los sectores productores de bienes y en los proveedores de algunos servicios muy específicos, como los de saneamiento y transporte-, el empleo verde presenta características que lo diferencian de los empleos de los demás asalariados registrados. Para analizar estas diferencias, se consideraron algunas variables disponibles en el Observatorio de Empleo y Dinámica Empresarial (OEDE) en 2015: las remuneraciones, el nivel de calificación requerido para el puesto y los porcentajes de varones y mujeres ${ }^{4}$.

Con respecto de la primera variable, se observa que los empleos verdes tienen remuneraciones un $20 \%$ más altas que el resto de los asalariados registrados. Dada su especialización sectorial, los empleos verdes tienen escasa representación en los sectores con remuneraciones más bajas, como el comercio, la construcción y los servicios, como la enseñanza.

La segunda variable tiene que ver con las ocupaciones. Los empleos verdes se desempeñan, en su mayoría, por trabajadores con calificaciones intermedias. Un porcentaje menor requiere trabajadores no calificados o altamente calificados. En efecto, el 58\% de los empleos verdes son desempeñados por los operarios, los artesanos y los trabajadores de oficios - casi duplicando el porcentaje de trabajadores con calificaciones intermedias del empleo formal total (30\%). Por otra parte, solo el $6 \%$ de los empleos verdes requiere calificación técnica o superior; esta categoría constituye aproximadamente el $13 \%$ del total del empleo asalariado registrado.

Con respecto de la tercera variable, solo el 13\% aproximadamente del empleo verde es desempeñado por mujeres (las mujeres representan el 39\% del empleo formal total). Debido a la elevada participación de los sectores de manufactura, de transporte y agropecuario, un gran porcentaje de empleos verdes es desempeñado por hombres. No obstante, el empleo verde público tiende a compensar la diferencia, ya que agrega mujeres. Los menores de 25 años desempeñan el $11 \%$ del empleo verde (los jóvenes constituyen el 13\% del empleo asalariado registrado total) y tienen una participación muy importante en el sector agropecuario, de la construcción y del turismo.

Las oportunidades para crear empleos verdes de mejor calidad se encuentran en aquellas actividades que incorporan más conocimientos y complejidad tecnológica. De este modo, los empleos verdes mejor remunerados se vinculan a la producción de las energías renovables, a la industria manufacturera -en particular, a las ramas con mayor intensidad tecnológica- y a los servicios profesionales. Estas actividades también presentan una mayor inserción laboral por parte de las mujeres y un mayor porcentaje de trabajadores con calificación técnica o superior.

Cabe destacar que los empleos verdes del sector productor de alimentos y bebidas -el que, aunque altamente competitivo en la Argentina, está incluido en la categoría de baja intensidad tecnológica por la Organización para la Cooperación y el Desarrollo Económicos (OCDE) - también presentan remuneraciones superiores al promedio.

4 Dado el alto nivel de desagregación sectorial, no fue posible realizar este análisis sobre la base de la Encuesta Permanente de Hogares. 


\section{Gráfico 2}

Argentina: características del empleo verde y del total del empleo asalariado registrado, 2015 (En porcentajes)

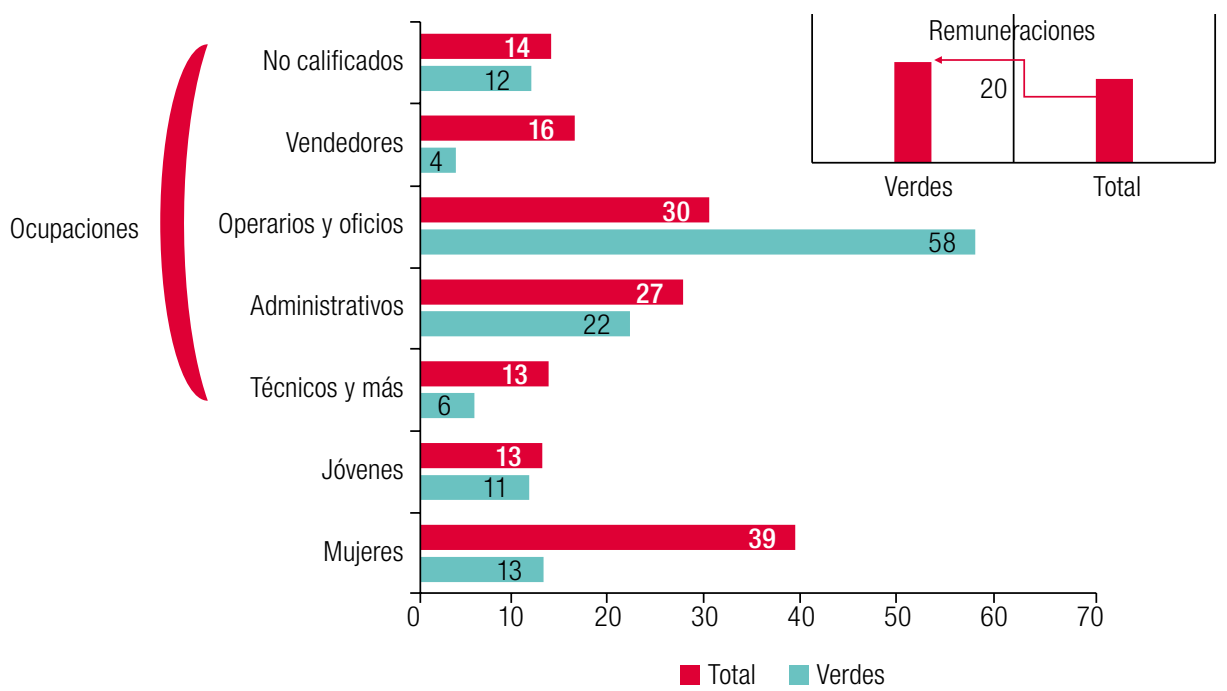

Fuente: Elaboración propia, sobre la base del Ministerio de Trabajo, Empleo y Seguridad Social (MTEySS).

Cuadro 2

Argentina: características del empleo verde por subsistemas

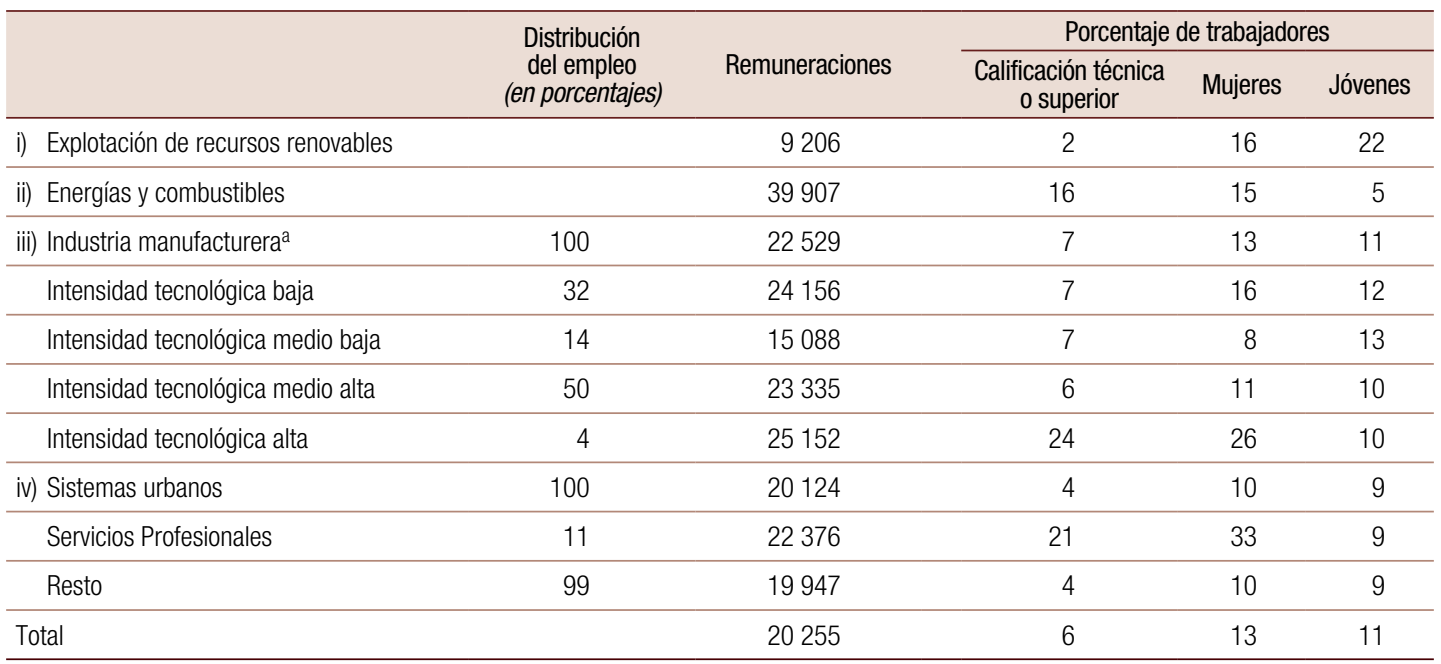

Fuente: Elaboración propia, sobre la base del Ministerio de Trabajo, Empleo y Seguridad Social (MTEySS).

a Se emplea la Clasificación de intensidad tecnológica según la Organización para la Cooperación y el Desarrollo Económicos (OCDE).

Los datos indican que los empleos verdes pueden tener mejores condiciones laborales que el resto de los empleos del sector formal y que esta situación se intensifica cuando las empresas pertenecen a los sectores que utilizan la tecnología de manera intensiva y que incorporan más conocimientos. Los mayores niveles de productividad permiten financiar mejores remuneraciones, más oportunidades de promoción laboral (es mayor el porcentaje de trabajadores altamente calificados) y una mayor inserción laboral para las mujeres. 


\section{Políticas públicas y empleo verde: algunos aspectos de la experiencia argentina}

La generación de empleos verdes depende, en gran media, de la capacidad para formular políticas públicas coordinadas y eficaces, orientadas a mejorar la sostenibilidad ambiental de algunos sectores y la calidad del empleo en otros. Asimismo, dichas políticas también deben orientarse a anticipar y mitigar los posibles efectos indeseados sobre el empleo.

Esto requiere un alto grado de integración, coherencia y coordinación entre las instituciones y las iniciativas desarrolladas (Lerda, Acquatella y Gómez, 2005), atributos que, a menudo, no se encuentran presentes en el contexto argentino (Rezk, 2005). En los últimos 25 años, los asuntos ambientales han cobrado mayor relevancia en la agenda política argentina, gracias a lo cual se han alcanzado avances importantes en su marco regulatorio. No obstante, la transición hacia una economía verde e inclusiva no forma parte aún de la política nacional de empleo, y el marco institucional, a su vez, sigue mostrando deficiencias en materia de coordinación.

En este sentido, se presentan a continuación algunos aspectos de la política ambiental en la Argentina, y se hace particular hincapié en aquellas iniciativas que contribuyen a la creación de empleos de calidad y a la transición hacia una economía verde.

\section{Relevancia de la temática ambiental en la agenda política y desarrollo del marco normativo}

La reforma constitucional de 1994 configuró la actual estructura de competencias en materia ambiental. A la Nación se le atribuyó la facultad de establecer leyes de presupuestos mínimos, mientras que a las provincias se les reservó la facultad de delinear el desarrollo legislativo de dichas leyes, reglamentándolas y complementándolas. Aunque coherentes con la naturaleza federal del país y su contexto territorial heterogéneo, la superposición normativa del marco regulatorio federal puede generar situaciones de ambigüedad y ralentizar su aplicación (Ábalos, 2011). En particular, en las áreas interdisciplinarias y transversales, como el ambiental, son frecuentes los problemas de coordinación a nivel vertical y horizontal (Rezk, 2005). Un ejemplo emblemático es la Ley 26.418/2010 de presupuestos mínimos para la protección de los glaciares. Los gobiernos provinciales, preocupados por las restricciones que la ley impone a las actividades económicas que se desarrollan alrededor de los glaciares, avanzaron legislaciones provinciales atribuyéndose la facultad normativa sobre la temática.

Si bien las cuestiones ambientales adquirieron más relevancia en la Argentina, se sigue observando la tendencia a no priorizarlas cuando se diseña la política. Así lo refleja el presupuesto nacional que se destinó a las actividades verdes en 2016: por cada peso destinado al medio ambiente se invirtieron 16 pesos en las actividades con impactos ambientales negativos (marrones) (Di Paola, 2017) .

Con frecuencia, las iniciativas ambientales se promueven para responder a situaciones ambientales complejas y no en virtud de una planificación estratégica y preventiva (CEMA, 2015). Tal es el caso de las leyes sobre la gestión de las cuencas hídricas, que surgieron como respuesta a las inundaciones y a la "batalla de Gualeguaychú" contra la construcción de las plantas papeleras. Por otra parte, la importancia del consumo responsable es aún incipiente en el ámbito local, y una buena parte de la producción con sellos ambientales responde a exigencias del comercio exterior. 
La escasa prioridad que se les da a los asuntos ambientales en el diseño de la política se observa también en las etapas de implementación y de monitoreo de las medidas. Un ejemplo es la aplicación parcial en la provincia de Buenos Aires de la ley sobre la aislación térmica de los edificios ${ }^{5}$, debido a la ausencia de un sistema eficaz de control y monitoreo (Vagge y Czajkowski, 2012). El rol pasivo de los consumidores, quienes no muestran interés alguno en exigir el cumplimiento de las normas, es un aspecto a destacar, que pone en evidencia la escasa incidencia del consumo responsable en el país.

\section{VII.Coordinación entre las políticas productivas, laborales y ambientales: el caso energético}

Tal vez como consecuencia de la escasa prioridad que se ha dado a las cuestiones ambientales en la agenda pública, las políticas ambientales, productivas y laborales no se han coordinado de la manera debida. Las políticas más establecidas han sido las de desarrollo productivo y estas, en general, no tienen un fuerte compromiso con los asuntos ambientales. No obstante, en los últimos años, se han observado buenas prácticas en las tres agendas de políticas, en particular, en las agendas de "política de desarrollo productivo verde".

El ejemplo más importante pertenece al área de las energías renovables. Con la Ley $27.191^{6}$ de 2015, el Gobierno de la Argentina expresó la voluntad de diversificar la oferta energética nacional a través de nuevas inversiones en las energías renovables, con el objeto de alejar al país de la dependencia de las fuentes fósiles y promover la generación de empleo. La expansión de las energías renovables genera empleo directo en las áreas rurales que, aunque ricas en recursos naturales renovables, se caracterizan por la escasez de oportunidades laborales para sus habitantes. La expansión de estas tecnologías en las áreas rurales aporta beneficios a la comunidad entera: la construcción de las nuevas infraestructuras o la mejora de las ya existentes da lugar a nuevas pymes y genera clusters de conocimientos para el desarrollo local. En este marco nacen una serie de programas, entre los que se destaca el plan RenovAr, con el que se espera reducir 2 millones de toneladas de carbono emitidas por año, lo que permitiría ahorrar 300 millones de dólares en combustibles y generar unos 5.000 a 8.000 empleos, directos e indirectos (Ministerio de Energía y Minería, 2016b).

La Argentina también formula políticas energéticas con finalidades sociales específicas. Por medio del programa PERMER, por ejemplo, se busca instalar sistemas eólicos o solares de generación energética en las zonas rurales y alejadas que no cuentan con los servicios adecuados de energía, agua caliente ni calefacción, ni los necesarios para cocinar. El proyecto es un valioso instrumento de política pública que integra objetivos económicos, sociales y ambientales. Otro ejemplo es la Ley de Promoción y Desarrollo de Energía Solar en Jujuy en la que, además de establecerse una política energética sostenible, se destaca que las inversiones contribuyen a disminuir la pobreza y a mitigar los efectos del cambio climático. La normativa da especial prioridad a los emprendimientos que favorecen cualitativa y cuantitativamente la creación de mano de obra jujeña y fortalecen la cadena de desarrollo de los proveedores locales ${ }^{8}$.

\footnotetext{
5 Ley 13.059, promulgada en 2010.

6 Régimen de Fomento Nacional para el uso de Fuentes Renovables de Energía destinada a la Producción de Energía Eléctrica. Se pretende alcanzar una contribución igual al $20 \%$ del consumo de energía eléctrica nacional del conjunto de las energías renovables para 2025

7 Ley 5.904, promulgada en 2016.

8 Art. 18, Ley 5.904 (Provincia de Jujuy), San Salvador de Jujuy, 25 de enero de 2016.
} 


\section{Elaboración de estudios de prospectiva y formalización del concepto de economía verde}

La planificación y el direccionamiento estratégicos de las políticas ambientales, integradas con el desarrollo productivo y la creación de trabajo decente y capaces de favorecer los procesos de desarrollo sostenible, requiere que se lleven a cabo estudios de diagnóstico eficaces. Se destacan, en este sentido, los estudios de prospectiva elaborados por el Ministerio de Ciencia y Tecnología, que han sido ampliamente debatidos a nivel nacional y local.

Dos casos emblemáticos son: 1) la iniciativa Pampa Azul, orientada, por un lado, a la exploración de las fronteras marinas y de su potencial para la generación de energía marina y, por otro, al monitoreo eficaz de las actividades pesqueras, y 2) el desarrollo de la bioeconomía en la Argentina ${ }^{9}$. Esta última iniciativa tiene el potencial de abarcar numerosas cadenas de valor interconectadas: la totalidad de las actividades agropecuarias, forestales, pesqueras y de acuicultura, de las industrias de alimentos y bebidas y de las industrias de pulpa y papel, así como ciertos segmentos de la industria química, farmacéutica, cosmética, textil y energética (Trigo, 2005). Ambos estudios contribuyen, en gran medida, al diseño de políticas industriales y de desarrollo que adquieren una perspectiva bioeconómica y favorecen la generación de empleo en los sectores de alta productividad.

Por último, si bien a nivel nacional no se hallan iniciativas públicas que se refieran específicamente a los conceptos de economía o empleo verde (Alzari, 2017), algunos ámbitos locales, como la Ciudad Autónoma de Buenos Aires (CABA) y Santa Fe, hacen referencia explícita a dichos conceptos. En la CABA, la economía verde es un área de trabajo activa y específica, y las autoridades de la ciudad reconocen y utilizan el concepto de empleo verde formulado por la OIT. La Ley 1.854/05, por ejemplo, no solo dicta un conjunto de medidas orientadas a la gestión eficaz y sostenible de los residuos, sino que formaliza a los recuperadores urbanos y los incluye dentro de un registro único obligatorio. Hasta el momento, se formalizaron 12 cooperativas y más de 5.300 recuperadores en la CABA ${ }^{10}$. La integración de estos conceptos en el marco normativo nacional podría constituir una herramienta valiosa para el crecimiento inclusivo y sostenible.

\section{Reflexiones finales}

La transición hacia una economía verde es un proceso en el que necesariamente la Argentina debe embarcarse. Los esfuerzos de adaptación para reducir la vulnerabilidad del país a los efectos del cambio climático, los compromisos asumidos para la mitigación de estos y la creciente conciencia de la sociedad respecto de la importancia de transitar senderos de desarrollo inclusivo que respeten el entorno son factores que están impulsando este proceso.

El desafío de avanzar hacia una economía verde y, a la vez, generar trabajo decente para las personas requiere una fuerte sinergia entre las políticas ambientales, económicas e industriales, así como las políticas laborales. Una economía sostenible como meta exige un cambio de modelo productivo hacia configuraciones más innovadoras, inteligentes, eficientes y competitivas.

La transición presenta oportunidades para la creación de nuevos empleos de calidad, que el país puede aprovechar si implementa las políticas adecuadas, pero también desafíos para algunos sectores que deberán transformarse, lo que conllevará una pérdida de empleos. Las políticas laborales y de protección social deben servir de apoyo a este proceso.

\footnotetext{
9 Véase [en línea] http://www.mincyt.gob.ar/accion/pampa-azul-9926; http://www.bioeconomia.mincyt.gob.ar.

10 Véase [en línea] http://uww.buenosaires.gob.ar/ciudadverde/separacion/separacion-en-origen/cooperativas-de-recuperadores-urbanos.
} 
La experiencia argentina muestra que los empleos verdes son el producto de los esfuerzos que realiza la sociedad hacia un desarrollo sostenible. En 2015, el 7\% de los empleos asalariados registrados del país eran empleos verdes. A pesar de hallarse en todos los sectores de la economía, predominaban en las actividades productoras de bienes y en servicios urbanos específicos, como el de saneamiento y transporte. Las regulaciones, las políticas públicas y las exigencias del comercio exterior parecen ser los principales factores que promueven la creación de este tipo de empleo, mientras que el consumo responsable aún no cumple el papel central que se observa en otras experiencias. En estos empleos, en promedio, los trabajadores se desempeñan en mejores condiciones laborales que el resto de los asalariados registrados (aunque se exhibe una menor inserción laboral por parte de las mujeres), condiciones que resultan aún mejores en aquellos subsectores que incorporan un bagaje más amplio de conocimientos.

Estos resultados muestran que la transición hacia una economía verde ofrece oportunidades para la creación de empleos de calidad y que desarrollar capacidades - de gestión, institucionales y productivas - resulta crucial para aprovecharlas.

En consecuencia, para que la transición hacia una economía verde sea justa, las políticas públicas han de considerar la dimensión laboral, lo que puede poner en marcha un círculo virtuoso de una economía más en armonía con el medio ambiente, más productiva y socialmente más inclusiva.

\section{Bibliografía}

Ábalos, M. G. (2011), "Ambiente y minería: distribución de competencias en el federalismo argentino", La Ley, Suplemento Constitucional, Buenos Aires, Thomson.

Altenburg, T. y C. Assmann (eds.), (2017), Green Industrial Policy. Concept, Policies, Country Experiences, Ginebra/Bonn, ONU-Medio Ambiente/Instituto Alemán de Desarrollo.

Altenburg, T. y D. Rodrik (2017), "Green Industrial Policy: Accelerating Structural Change towards Wealthy Green Economies”, Green Industrial Policy. Concept, Policies, Country Experiences, T. Altenburg y C. Assmann (eds.), Ginebra/Bonn, ONU-Medio Ambiente/Instituto Alemán de Desarrollo.

Alzari, M. J. (2017), Estado de arte en materia de empleo y economía verde en Argentina: las políticas, regulaciones e iniciativas privadas (sociedad civil, empresas) a nivel nacional y provincial, Buenos Aires, inédito.

Amarante, V. y R. Arim (2015), Desigualdad e informalidad: un análisis de cinco experiencias latinoamericanas, Libros de la CEPAL, № 133 (LC/G.2637-P), Santiago, Comisión Económica para América Latina y el Caribe (CEPAL).

Bertranou, F. y L. Casanova (2013), Informalidad laboral en Argentina: segmentos críticos y políticas para la formalización, Buenos Aires, Organización Internacional del Trabajo (OIT).

CEMA (Cámara Empresaria de Medio Ambiente) (2015), Propuestas de políticas ambientales para la Argentina que viene, Buenos Aires.

CEPAL (Comisión Económica para América Latina y el Caribe) (2016), Horizontes 2030: la igualdad en el centro del desarrollo sostenible (LC/G.2660/Rev.1), Santiago.

CIFRA (Centro de Investigación y Formación de la República Argentina) (2011), "Rentabilidad, empleo y condiciones de trabajo en el sector agropecuario", Documento de Trabajo, № 8, Buenos Aires.

Comisión Europea y otros (2016), Sistema de Cuentas Nacionales 2008 (ST/ESA/STAT/SER.F/2/Rev.5), Nueva York [en línea] https://unstats.un.org/unsd/nationalaccount/docs/SNA2008Spanish.pdf.

Di Paola, M. (2017), "El presupuesto climático rumbo al 2017: todo sigue igual", Informe ambiental anual 2017, Buenos Aires, Fundación Ambiente y Recursos Naturales (FARN).

Domínguez, M. y otros (2016), Escenarios sobre calidad e inocuidad en el sector productor de materias primas y alimentos elaborados en Argentina (2030), Buenos Aires, Ministerio de Ciencia, Tecnología e Innovación Productiva (MINCyT).

Eurostat (Oficina Estadística de las Comunidades Europeas) (2009), The Environmental Goods and Services Sector. A Data Collection Handbook, Luxemburgo, Comisión Europea.

FAO (Organización de las Naciones Unidas para la Alimentación y la Agricultura) (2014), Evaluación de los recursos forestales mundiales 2015. Informe Nacional Argentina, Roma [en línea] http://www.fao. org/3/a-az153s.pdf. 
INDEC (Instituto Nacional de Estadística y Censos), Censo nacional de población, hogares y viviendas 2010. Censo del Bicentenario. Resultados definitivos, Serie $B N^{\circ} 2$, tomo 1, Buenos Aires [en línea] https:// www.indec.gob.ar/ftp/cuadros/poblacion/censo2010_tomo1.pdf.

Infante, R. y P. Gerstenfeld (eds.) (2013), Hacia un desarrollo inclusivo: el caso de la Argentina (LC/L.3569), Santiago, Comisión Económica para América Latina y el Caribe (CEPAL)/Organización Internacional del Trabajo (OIT).

INTI (Instituto Nacional de Tecnología Industrial) (2013), “Generadores eólicos: el tamaño sí importa”, Buenos Aires. IPCC (Grupo Intergubernamental de Expertos sobre el Cambio Climático) (2015), Cambio climático 2014. Informe de síntesis, Ginebra, Organización Metereológica Mundial (OMM)/Programa de las Naciones Unidas para el Medio Ambiente (PNUMA).

Jarvis, A., A. Varma y J. Ram (2011), Assessing Green Jobs Potential in Developing Countries: A Practitioner's Guide, Ginebra, Organización Internacional del Trabajo (OIT).

Keivani, R. y otros (2010), "Green Jobs Creation through Sustainable Refurbishment in the Developing Countries", Working Paper, № WP275, Ginebra, Organización Internacional del Trabajo (OIT).

Lerda, J., J. Acquatella y J. J. Gómez (2005), "Coordinación de políticas públicas: desafíos y oportunidades para una agenda fiscal-ambiental”, Política fiscal y medio ambiente: bases para una agenda común, Libros de la CEPAL, № 85 (LC/G.2274-P), J. Acquatella y A. Bárcena (eds.), Santiago, Comisión Económica para América Latina y el Caribe (CEPAL).

MAyDS (Ministerio de Ambiente y Desarrollo Sustentable) (2017a), Informe del estado del ambiente 2016, Buenos Aires. (2017b), Inventario nacional de gases de efecto invernadero, Buenos Aires.

Ministerio de Energía y Minería (2016a), "Balance Energético Nacional 2015", Buenos Aires. (2016b), RenovAr, Plan de Energías Renovables, Argentina 2016-2025, Ronda 1: Ilamado a convocatoria abierta nacional e internacional, julio.

MTEySS (Ministerio de Trabajo, Empleo y Seguridad Social) (s/f), "Boletín de estadísticas laborales (BEL)", Buenos Aires.

(n/db), "Observatorio de empleo y dinámica empresarial", Buenos Aires.

OCDE (Organización de Cooperación y Desarrollo Económicos) (2017), Employment Implications of Green Growth: Linking Jobs, Growth, and Green Policies, París, OECD Publishing.

OCDE/Eurostat (Organización de Cooperación y Desarrollo Económicos/Oficina Estadística de las Comunidades Europeas) (1999), The Environmental Goods and Services Industry: Manual for Data Collection and Analysis, París, OECD Publishing.

Ohaco, M. (2012), "Precariedad y no registro en los trabajadores asalariados rurales de la Argentina", Trabajo, ocupación y empleo, Buenos Aires, Ministerio de Trabajo, Empleo y Seguridad Social.

OIT (Organización Internacional del Trabajo) (2017), Estimación del empleo verde en Argentina, Buenos Aires, inédito.

(2016), Empleos verdes para un desarrollo sostenible. El caso uruguayo, Montevideo.

(2015), Directrices de política para una transición justa hacia economías y sociedades ambientalmente sostenibles para todos, Ginebra. (2013a), Evaluation of the Potential of Green Jobs in Mexico, Ginebra.

(2013b), El desarrollo sostenible, el trabajo decente y los empleos verdes, Ginebra.

(2012), Hacia el desarrollo sostenible: oportunidades de trabajo decente e inclusión social en una economía verde, Ginebra.

(2011), Piso de protección social para una globalización equitativa e inclusiva. Informe del Grupo consultivo presidido por Michelle Bachelet, Ginebra.

(2010), "Cambio climático y trabajo: la necesidad de una 'transición justa'”, Boletín Internacional de Investigación Sindical, vol. 2. № 2, Ginebra.

(2009), Empregos verdes no Brasil: quantos são, onde estão e como evoluirão nos próximos anos, Brasilia.

PNUMA (Programa de las Naciones Unidas para el Medio Ambiente) y otros (2008), Green Jobs: Towards Decent Work in a Sustainable, Low-Carbon World, Nairobi, Programa de las Naciones Unidas para el Medio Ambiente (PNUMA).

Rezk, E. (2005), "Fallas de coordinación: desafíos de política para el federalismo fiscal-ambiental argentino", serie Medio Ambiente y Desarrollo, № 115 (LC/L.2428-P), Santiago, Comisión Económica para América Latina y el Caribe (CEPAL).

Rodríguez, J. (2005), "Los complejos agroalimentarios y el empleo: una controversia teórica y empírica", Documento de Trabajo, № 3, Buenos Aires, Centro de Estudios para el Desarrollo Argentino (CENDA). 
SAyDS (Secretaría de Ambiente y Desarrollo Sustentable) (2015), Primer reporte de actualización bienal de la República Argentina ante la Convención Marco de las Naciones Unidas sobre el cambio climático, Buenos Aires.

Stern, N. (2006), The Economics of Climate Change: The Stern Review, Cambridge, Cambridge University Press.

Stumpo, G. y D. Rivas (comps.) (2013), La industria argentina frente a los nuevos desafíos y oportunidades del siglo XXI (LC/L.3637), Santiago, Comisión Económica para América Latina y el Caribe (CEPAL).

Sugathan, M. (2013), Lists of Environmental Goods: An Overview, Ginebra, Centro Internacional de Comercio y Desarrollo Sostenible.

Sustainlabor (Fundación Laboral Internacional para el Desarrollo Sostenible) (2009), Las trabajadoras y los empleos verdes: empleo, equidad, igualdad [en línea] http://apgreenjobs.ilo.org/resources/green-jobsand-women-workers-employment-equity-equality.

Trigo, E. (2005), Reflexiones sobre las oportunidades que ofrece la biotecnología agropecuaria a los países de América Latina y el Caribe y las opciones de políticas a impulsar para su desarrollo, Buenos Aires [en línea] http://www.pymesonline.com/uploads/tx_icticontent/R01938_biotecnologia.pdf.

Vagge, C. y J. Czajkowski (2012), "Impacto de la aplicación de la Ley 13.059 de Eficiencia Energética en relación a la nueva Ordenanza de Usos del Suelo de la ciudad de La Plata y la Norma IRAM 11900 de Etiquetado de Edificios", Ambiente Construído, vol. 12, № 2, Porto Alegre, Asociación Nacional de Tecnología del Ambiente Construido.

Viglizzo, E. y F. Frank (2010), "Erosión del suelo y contaminación del ambiente", Expansión de la frontera agropecuaria en Argentina y su impacto ecológico-ambiental, E. Viglizzo y E. Jobbágy (eds.), Buenos Aires, Instituto Nacional de Tecnología Agropecuaria (INTA) [en línea] http://catalog.ipbes.net/system/ assessment/3/references/files/16/original/50._Argentina_Expansi\%C3\%B3n_Frontera_Agropecuaria_2010. pdf?1346944833.

Voices Research and Consultancy (2016), Radar de sustentabilidad 2015, Buenos Aires.

World Bank (2016), "Análisis ambiental de país: Argentina", Serie de informes técnicos del Banco Mundial en Argentina, Paraguay y Uruguay, № 9, Washington, D.C. 


\section{Anexo A1}

\section{Metodología para la estimación del empleo verde en la Argentina}

En este anexo se resumen los principales aspectos del capítulo metodológico de la investigación Estimación del empleo verde en Argentina, en la que se enmarca este artículo (OIT, 2017).

\section{Definición de empleo verde en la Argentina}

El empleo verde es aquel que se genera en una economía verde y que considera, al mismo tiempo, las dimensiones económicas, sociales y ambientales. Para incluir un empleo en esta categoría, las actividades laborales deben desarrollarse en sectores con sostenibilidad ambiental, y el empleo debe cumplir con los estándares del trabajo decente - un concepto definido por la OIT, que establece las características que debe reunir una relación laboral para que el trabajo se realice "en condiciones de libertad, igualdad, seguridad y dignidad humana" (OIT, 2012).

\section{Estrategia de la estimación}

La metodología que se utilizó para estimar el empleo verde en la Argentina se extrajo del manual Assessing green jobs potential in developing countries: a practitioner's guide (Jarvis, Varma y Ram, 2011). Con un enfoque de método mixto, se emplearon diversas técnicas, como la recopilación de información estadística y de información cualitativa a partir de entrevistas a informantes clave y el análisis de datos cuantitativos de distintas fuentes.

El proceso se desarrolló en tres grandes etapas. La primera etapa consistió en analizar los vínculos entre las dimensiones productiva, ambiental y laboral en toda la economía, por medio de un análisis exhaustivo de la bibliografía y la normativa ambiental y laboral, y de las entrevistas a informantes clave. En segundo lugar, se estimaron los sectores, subsectores y conjuntos de empresas que ejercen las buenas prácticas ambientales y se analizaron las condiciones laborales. La tercera etapa consistió en validar los resultados obtenidos en talleres y en reuniones con referentes sectoriales, atendiendo a la lógica tripartita de la OIT.

\section{Criterios para identificar sectores verdes}

En el estudio de la Argentina, se siguieron dos criterios centrales para identificar los sectores verdes: i) las actividades productoras de bienes y servicios ambientales y ii) las empresas que ejercen las buenas prácticas ambientales en distintos sectores de la estructura productiva.

Las actividades que producen bienes y servicios ambientales se identificaron a partir de la experiencia internacional (OCDE/Eurostat, 1999; OCDE, 2017; Eurostat, 2009; PNUMA y otros, 2008). Estas actividades se evaluaron en el ámbito local antes de considerarlas verdes para la Argentina.

Algunos criterios para determinar las actividades verdes escapan a la lógica de los sectores productivos y muestran la heterogeneidad que puede exhibir el interior de una rama de actividad determinada o de una región: en un mismo momento, algunos productores realizan esfuerzos para instaurar modos ambientalmente más sostenibles, mientras que otros no. En el diagrama A1.1 se puede observar un resumen de estos criterios. 
Diagrama A1.1

Criterios para identificar los sectores verdes

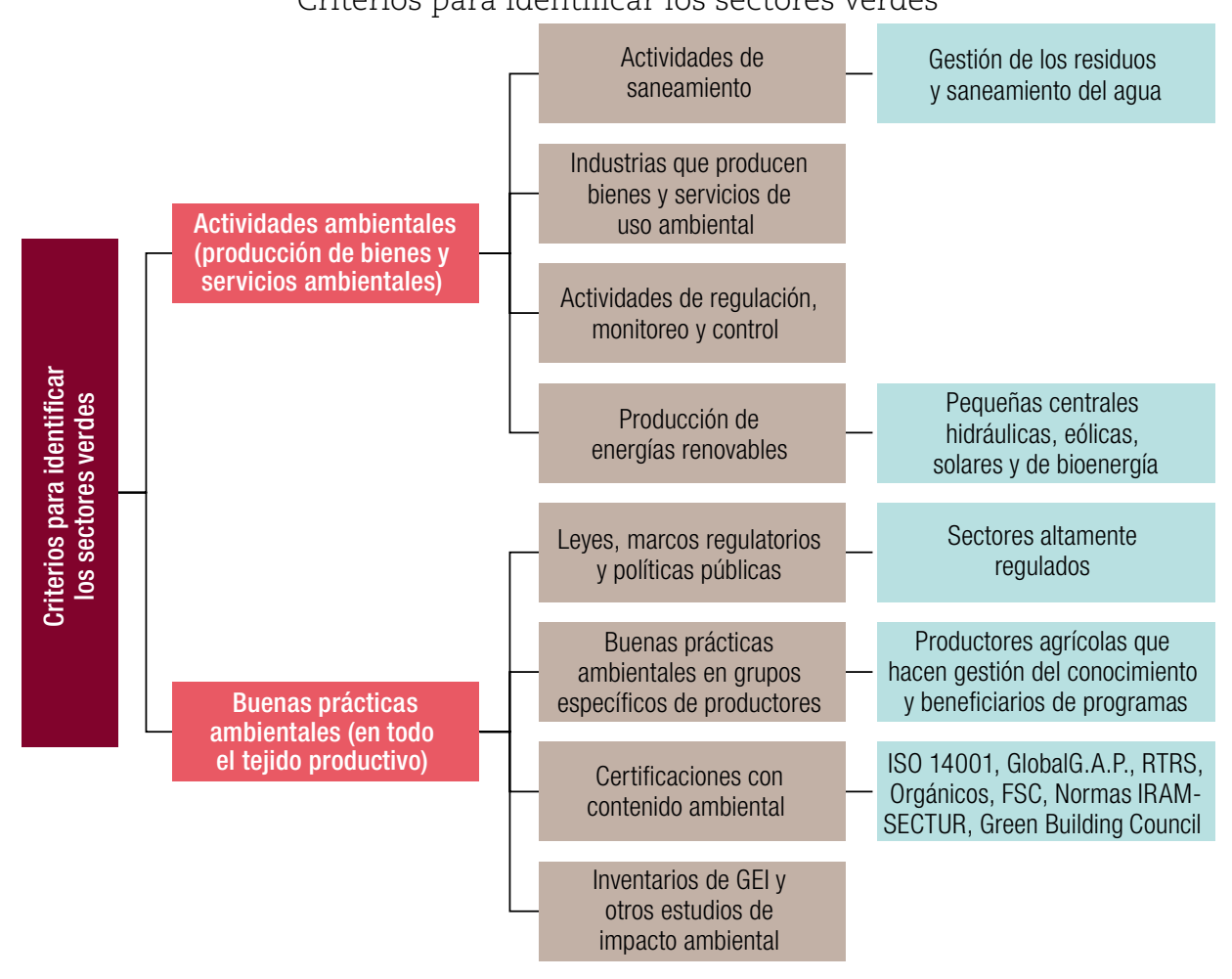

Fuente: Elaboración propia.

\section{Trabajo decente}

Para identificar el trabajo decente en el estudio de la Argentina, se consideró como variable proxy al empleo asalariado que aporta al sistema de seguridad social. La tasa de afiliación sindical en la Argentina es elevada. El país cuenta con una política de salario mínimo, vital y móvil y con una negociación colectiva activa que actualiza los básicos de los convenios. No obstante, a estos beneficios los obtienen, en gran medida, los asalariados inscritos. También se analizó la inserción laboral de las mujeres en la rama como una forma de aproximarse a la dimensión del trabajo decente vinculada a la creación de oportunidades laborales para los distintos perfiles de trabajadores.

\section{Unidad de análisis}

Se considera empleo verde a todo aquel que alcanza los estándares de trabajo decente y que se desempeña en empresas con sostenibilidad ambiental. El estudio no alcanza a desagregar las "ocupaciones verdes".

\section{Fuentes de información}

Para estimar el empleo, la principal fuente que se utilizó fue el Observatorio de Empleo y Dinámica Empresarial (OEDE). Las condiciones laborales se evaluaron principalmente sobre la base de las Encuestas Permanentes de Hogares (Instituto Nacional de Estadística y Censos de la República Argentina, INDEC), la Encuesta de Trabajadores (Ministerio de Trabajo) y el sistema de indicadores de siniestralidad (Superintendencia de Riesgos del Trabajo, SRT). 